\title{
Research on MIL Search Method for P2P Borrowing Loss Clients Based on Social Network Perspective
}

\author{
Sulin Pang1,2, Junkun Yang1,2 \\ ${ }^{1}$ School of Management/School of Emergency Management, Jinan University, Guangzhou, China \\ ${ }^{2}$ Guangdong Emergency Technology Research Center of Risk Evaluation and Prewarning on Public Network Security, \\ Guangzhou, China \\ Email: yangjk@linklearn.cn
}

How to cite this paper: Pang, S.L. and Yang, J.K. (2018) Research on MIL Search Method for P2P Borrowing Loss Clients Based on Social Network Perspective. Open Journal of Social Sciences, 6, 108-120. https://doi.org/10.4236/jss.2018.611007

Received: September 3, 2018

Accepted: November 9, 2018

Published: November 12, 2018

Copyright ( 92018 by authors and Scientific Research Publishing Inc. This work is licensed under the Creative Commons Attribution International License (CC BY 4.0).

http://creativecommons.org/licenses/by/4.0/

(c) (i) Open Access

\begin{abstract}
This paper proposes a multi-indicator search study based on the social network perspective for borrowing and lending customers. When studying P2P lending and losing customers, according to the division of interpersonal relationship in sociology and the extent to which the client can be debited in reality, it is divided into three kinds of relationship networks: blood relationship network, geo-relationship network and business relationship network, assisting to combine the two-mode subordinate network of the lost customers, and focusing on analyzing its scale, density and other indicators, and hope to find the target lost customers. Key figures in the social network of interpersonal relationships, message communicators, behavioral influencers, etc., to achieve the search for lending customers after their sudden loss. For the first time, this paper applies the social network theory to the search for borrowed and lost customers and proposes the MIL algorithm. It proposes a new idea for the hiddenness of the loan client's loss of connection, and accelerates the governance of the ill-fated phenomenon of loan and loan loss effectiveness. This paper also analyzes the case and proposes relevant suggestions in connection with a loss event in Guangzhou.
\end{abstract}

\section{Keywords}

Loan and Loss, Social Network, Social Norms, Shortest Path

\section{Introduction}

In recent years, with the growing difficulties of SMEs' main loans, private capital has become more and more large, and some open cities have allowed "private 
capital" to connect with SMEs, resulting in so-ca risky characteristics are likely to cause many problems. The lending procedures for P2P lending are generally incomplete, there is no secured mortgage, and the relevant legal guarantees are not perfect. The current $\mathrm{P} 2 \mathrm{P}$ lending is mostly Fund transactions conducted under semi-public or even private conditions are closely related to the so-called creditworthiness of both borrowers and lenders. Such transactions can easily lead to disputes and the solutions are not scientific enough if they encounter changes in circumstances. Ashta (2010) [1] found P2P lending is more of an ambition than a reality. Although Web 2.0 technology provides a new means of mobilizing funds, the lending mechanism at work follows the mainstream traditional loan management approach. At present, China's credit system is still not perfect, and citizens' awareness of their own credit is generally not high, which has led to the current high incidence of $\mathrm{P} 2 \mathrm{P}$ lending. In order to facilitate the lending process, $\mathrm{P} 2 \mathrm{P}$ lending has insufficient information on most borrowing customers, especially if there is insufficient information such as collateral and financial information, so that once the lending customers lose contact, we will have nowhere to look for, given China Society has always been a society connected by interpersonal relationships, so it is of great significance for P2P lending customers to use social network search tools. At present, there is basically no research on foreign social network to search for lost customers. We believe that the possible reasons are due to the long-term construction of foreign credit system, and the default rate of default is relatively low. On the one hand, due to China's special national conditions, it leads to lost customers. The concealment is high and difficult to find. Through reading a large amount of literature, we find that the current research at home and abroad mainly focuses on two aspects: the role of social networks in P2P lending and social network analysis.

P2P online lending as an innovative financial service generated by Internet + private lending, not only depends on the technology provided by the Internet and more and more mature e-commerce applications, but also depends on the unsecured, unsecured lending form, one relies on mutual contact. The social network can also successfully help you get the idea of lending. At home and abroad, a lot of research has been done on the introduction of social network factors in the research of P2P lending platform. Martina E (2010) [2] found that Prosper has paid more attention to introducing user borrowing history in user credit evaluation, friends. The relationship and the status of the social organization in which it is located are evaluated for credit. Moreover, with the rapid development of the $\mathrm{P} 2 \mathrm{P}$ online lending platform and the gradual expansion of the user scale, the connection between the P2P lending platform and other social platforms has gradually become closer. Lin M (2009) [3] uses a large sample of the complete and failed list of Prosper.com, the largest online P2P lending market, to test whether social networks lead to better loan outcomes and find that online social networks can alleviate information on both borrowers and lenders. Asymmetry can inhibit the risk of default. Armendáriz B (2010) [4] studied the $\mathrm{P} 2 \mathrm{P}$ online lending platform by combining theoretical and empirical data, and 
believed that social networks can effectively curb the occurrence of adverse selection and moral hazard, and urge borrowers to repay on time. Freedman $S$ (2017) [5] studied whether leading P2P lending sites use social network data to promote online markets. It has been found that borrowers with social relationships are more likely to obtain loans and obtain lower interest rates; Chen, X.; Zhou, L.; Wan, D. (2016) [6] studied individual social capital and P2P finance. The relationship between loan outcomes in the credit market found that the borrower's general group social capital (i.e., group membership) and relational social capital (i.e., group credibility and verifiability and group trust) produced inconsistent effects. Lin M (2013) [7] draws on financial data and social network literature to study whether and how network metrics affect financial transactions in the market. The results show that the relationship between online social networks helps to alleviate information asymmetry in the loan process. People with more abundant online resources are more likely to obtain loans at low cost. If the borrowing and lending parties are relatives or friends, the default rate is significantly reduced. The key success factor of the industry is to better reveal and utilize the soft credit information embedded in the social network.

The characteristics and analysis methods of social networks are another perspective of understanding social networks, focusing on the perspective of social network structure and the influencing factors of social network strength. It generally includes an analysis of network density and network centrality. Izquierdo L, and Hanneman R. (2006) [8] first proposed the concept of network density and centrality in the introduction of formal analysis of social networks. It is the closeness of the connection between various points on the way. Granovetter M S. (1973) [9] first proposed the concept of social network strength, and distinguished the strong relationship from the weak relationship, and considered that the strong relationship is the gender and age of the individual. Social and economic characteristics such as education and occupation are similarly formed, while weak relationships are developed among individuals with different socio-economic characteristics. Ron Burt (1996) [10] first proposed the "structural hole" theory, and believed that the strength of the individual social network is not related to the amount of social resources it has, but depends on the number of structural holes he occupies. Reveal the essence of the relationship. In addition, the strength of social network relations is also related to the formation of social relations. McKenney, Dave, White, Tony (2017) [11] mainly contributed to the method of selecting the transfer entropy threshold, which determines whether a link should be considered. It is influential. These methods can be used to identify unknown links in the network or to prunes known links that do not actually represent a real impact relationship. Hock, Karlo, Ng, Kah Loon, Fefferman, Nina H (2010) [12], we tested the predictions of social behaviors that help individuals to be highlighted in social groups that may conflict with the potential of their social environment. In summary, the general social network analysis perspective is central, density, scale, etc., and the measurement indicators generally vary according to the research object. 
Social network research on the constraints and identification of P2P borrowers and borrowers: Karlan (2007) [13] social networks can implement certain social sanctions, causing defaulters to suffer reputation losses, and even excluded from the network, thereby reducing defaults. Lee (2012) [14] using a large number of daily data samples from one of Korea's largest P2P lending platforms to study lender behavior in the peer-to-peer (P2P) lending market, we find strong evidence that, as tenders progress, The herd effect and marginal effect are diminishing. Based on trust theory, D Chen (2014) [15] developed a comprehensive trust model for online P2P lending environments to better understand the key factors driving lenders' trust. M Malekipirbazari, V Aksakalli (2015) [16] proposed a classification method based on random forest (RF) to predict the state of borrowers to identify good borrowers. L Puro (2010) [17] introduced borrower decision assistance, which will help to formalize the borrower's decision-making process in a particular P2P loan. BC Collier (2010) [18] By embedding personal reputation in the community's reputation, incentives allow peers to choose high-quality borrowers and generate more expensive information signals, thereby reducing the typical adverse selection in any agent relationship and Moral hazard risk. B Luo (2013) [19] through the decision tree, we model the formation of grazing when decision makers with heterogeneous preferences face expensive information acquisition and analysis. An empirical analysis was also conducted to address the impact of herd behavior on personal interests. $S$ Freedman (2017) [5] found that borrowers with social relationships have been more likely to obtain loans and receive lower interest rates; however, most borrowers without social relationships are more likely to be late or default. We provide evidence that these findings are driven by the relationship between the lender's incomplete understanding of social relationships and the quality of undiscovered borrowers. ÁE Carrillo (2017) [20] provides an overview of the measurement methods that measure the different dimensions and scales of social capital, as well as the mechanisms that underestimate the accuracy of measurement. RE Kraut (2012) [21] provides lessons from social science theory and empirical research that can help improve the design of online communities. Social science can tell us a lot about how to make online communities thrive, provide personal motivation and human behavior, and explain them correctly, providing information for specific design choices for online communities.

Based on the concealment and universality of the lost customers, this phenomenon has a tendency to continue to spread because of the difficulty of finding and the difficulty of implementation. The main work of this paper is to apply the social network theory to search for P2P lending and losing customers based on the P2P lending mainly to maintain the transaction with credit. The second part introduces how to carry out the interpersonal social network of the lost group according to the characteristics of the lost group. The classification and relationship strength values are determined, and the personal social network and the two-mode subordinate network for the disjointed group are established. The third part is the description of the analysis of the personal interpersonal social 
network algorithm. By analyzing the personal social network, the key to multi-path the node and its two-mode membership network, the fourth part is a theoretical simplified analysis combined with a case of loss of association, the fifth part is the summary and recommendations. Exploring a summary and suggestions on how to use the social network method for those who have lost their associations under the premise that China's current credit system is not perfect.

\section{Personal Social Network Establishment}

\subsection{Selection of Personal Interpersonal Social Network Indicators}

First of all, the borrowing and lending customers studied in this paper mainly refer to those incomplete lending procedures, no secured mortgages, and the so-called credit maintenance of both borrowers and lenders. Therefore, the cost of customer credit loss is very low. Once communication devices such as mobile phones are lost, it is difficult for us to find them, so we chose the P2P loan lending group as the research object. Secondly, based on the social network perspective, the search for the lost customer is aimed at the social network relationship of the borrowing customer, by describing its social network and related algorithms, and querying The key people in the network, or the core characters in the connected network, or the message communicators in the network, to make up for the incompleteness of the borrowing procedures through the information in the interpersonal social network. The problem from the perspective of sociology, the network of interpersonal relationships is divided into: blood relationship network, geopolitical relationship network and business relationship network. The acquisition of data nodes in the network, we mainly through the nomination method, the main steps are to say some people who have some relationship with themselves, and then say what is the relationship between these people, here we will get the three in the network survey The classification is divided into three different issues to consider. This article mainly considers the following issues:

1) The blood network (except for immediate family members) mainly involves:

a) Which relatives do you often eat with?

b) Which relatives do you usually have money with?

c) Which relatives are you most happy to trust?

2) The geo-network mainly involves:

a) He is a very good friend

b) You know his work unit and contact information

c) You know his parents

3) Industry relationship mainly involves

a) You want to know the job information and hot news, etc., who will you discuss with?

b) You have difficulties in life and work, who are you looking for?

c) Who do you often work with to complete the task at work? 
4) The two-mode subordinate network mainly involves

a) Where do you meet or meet most often?

b) When is the most common time when you meet with him?

c) When you are somewhere, you most often think about who you are about.

According to the above aspects, we will get the nodes associated with the target three different networks. For each associated node of the target node, they will be considered at the same angle. In the real relationship network, these nodes may have certain Repeat, we will be involved in the actual level of the second level (friends of friends), and then we assign the strength of the relationship between nodes according to the frequency of communication.

\subsection{Personal Affiliation Network}

The two-mode network is composed of two groups of different attributes, which can be people. The time is from 5 am to 7 am, events, such as hotels, cafes, banks, supermarkets, schools, etc., are used to describe a group of people. With the relationship between another group, we can get some different messages through the conversion of the two-mode network. The two-mode sub-social network to be collected in this paper is based on the association between the three elements of people, location and time (see Table 1 ).

The main data we collect here is from the target customers and key people in their social networks. We can draw from the same location based on their people-site infrastructure network and people-time infrastructure network. Two people who appear together, and two people who often appear at the same time, time-location networks and derived location-location networks and time-time networks based on shared individuals. Due to the particularity of this research question, this network does not function. Big, Ignore its role here, no discussion.

\section{Algorithm Research}

\subsection{Algorithm thought Description}

Based on the personal interpersonal social network constructed in the previous section, we will analyze the acquired network. This algorithm includes the multi-path search between the confirmed query target and the key nodes in the network. At present, most of the research on the shortest path algorithm can only determine the shortest path between two nodes. Before searching for the shortest path, it does not filter the nodes in the network, and the efficiency is relatively low. The group interpersonal relationship network is based on the network

Table 1. Personal two-model membership network construction table.

\begin{tabular}{cc}
\hline Basic network type & Derived network type \\
\hline $\begin{array}{c}\text { People-location } \\
\text { basic network }\end{array}$ & $\begin{array}{c}\text { People-location basic network derived person-person network } \\
\text { People-location basic network derived location-location network } \\
\text { People-time } \\
\text { basic network }\end{array}$ \\
\end{tabular}


constructed by the disjointed group, relatives, friends, etc. to explore its centrality, relevance and other indicators, and to explain, and then explore the central indicators and other indicators to obtain the first influential strength point of the individual interpersonal social network. a judgment, and then find the shortest path between the target individual and the strong point set, and in real life, especially the speciality and concealment of the network of interpersonal relationships in the lost group, many node individuals will not be for various reasons. It helps us to find the lost individuals, and it does not match the theoretical shortest path. Therefore, not only the shortest path is required, but also the multiple suboptimal paths when some individual nodes suddenly lose contact or refuse to cooperate with the shortest path.

\subsection{Related Definitions}

Intermediate centrality indicator: It measures the degree of actor's control over resources. If we want to connect with a lost customer, we must pass someone. We can think that this person is in an important position. There are two kinds of intermediate centrality. The species is the absolute intermediate degree, and the other is the standardized intermediate center, which can be used to compare the intermediate centers of points in different network diagrams:

$$
\begin{gathered}
C_{R B i}=\frac{2 C_{A B i}}{n^{2}-3 n+2} \\
c_{A B i}=\sum_{j}^{n} \sum_{k}^{n} b_{j k}(i), j \neq k \neq i, j<k
\end{gathered}
$$

Point-centered indicator: If the point of a point is large, it is considered to be active. At the center position, the point center of the node can be divided into two categories, that is, the absolute point center degree and the point The number of directly connected points, expressed as the maximum possible degree at any point in a point map, is expressed relative to the center of the point. Here we use the relative centrality index to facilitate comparison of different networks; :

$$
\begin{gathered}
C_{R D}(x)=\frac{C_{A D}(x)}{n-1} \\
\text { path }_{A i} \& \& \text { path }_{i B}=\operatorname{ConCheck}\left\{\operatorname{Togg}\left(\text { path }_{A i}, \text { path }_{i B}\right)\right\}
\end{gathered}
$$

$\operatorname{Togg}\left(\right.$ path $_{A i}$, path $\left._{i B}\right)$ indicates a new path obtained by adding path $_{i B}$ after path path $_{A i}$, ConCheck \{\} indicates that $\operatorname{Togg}\{\}$ is checked, there is no same node in it, and it is retained. Otherwise, it is deleted.

\subsection{MIL Algorithm (Multipath Inquire Lost)}

The algorithm steps are as follows:

Step 1: Calculate the intermediate centrality indicator $c_{R B i}$. Calculate the node with the largest index value and perform network split based on this node.

Step 2: Based on the classical algorithm Dijkstra, find the shortest path from the starting node to the key node in the split network. $l$ is the number of shortest 
path nodes, and $i=1$ is set.

Step 3: If $i<l$, delete the edge between $i$ and $(i+1)$ in the shortest path path, continue to calculate the shortest path path $_{A i}$ of the starting node $A$ to $(i+1)$, and then splicing the link of path to the node $\mathrm{K}$ on the shortest path $(i+1)$ to $B$. After that, remember the new path:

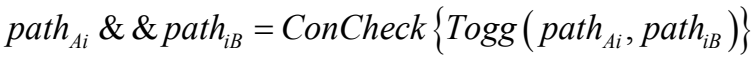

Otherwise exit.

Step 4: Restore the edge between the $i$ and $(i+1)$ nodes, $(i+1)$, and return to step 3 .

Step 5: According to the calculated set of nodes above the multiple paths, construct a two-mode network, and calculate the degree centrality index $C_{R D}(x)$.

\section{Case Analysis and Application}

\subsection{Case Introduction}

Wang, who lives in Guangzhou, is an ordinary worker. Because his father has more savings, Wang likes to do small business when he goes to work. Living in Guangzhou, many people around are participating in $\mathrm{P} 2 \mathrm{P}$ lending. Whether it is financing to do business or lending to collect interest, Wang has set his mind to plan to finance a factory. Although the factory is not large, the required funds are not small. After lending 1 million yuan in the bank, he borrowed 1 million yuan through P2P lending.

After that, the industry was in a downturn and prices fell sharply. Due to the backlog of stocks and the slowdown in production capacity, the raw materials of Wang's factory were affected. After the performance of the situation, one year later, Wang could not hold back, and the factory was discontinued. After the production was stopped, Wang's equipment did not find the buyer, and the piles of raw materials and the produced products were not processed there. As an investor who borrows money from the factory owner, the days of the army are miserable. Wang did not see the trace. At the beginning, the army lent the money for Zhang Ming did not pledge, and no one made a guarantee. After Wang disappeared, the army left a document.

\subsection{Case Analysis}

This is a typical case in which P2P lending gives a lot of damage to the borrower. In the case, the borrowers and the lenders only guarantee through the credibility and emotion, and there is no valid contract. Although the two are companions who have been together for many years, the army as the lender does not have Have a systematic understanding of Wang's interpersonal relationships, etc., the application of social networking tools.

In combination with this case, we try to use the social network method to try to analyze how to quickly find the lost Wang. First of all, when Wang did not repay the interest in time, and the factory apparently had a mismanagement sit- 
uation, when the loss of the joint signal was frequently displayed, the army as the lender should collect the information in time and pay close attention to the situation of Wang.

Here, taking the industry network as an example, according to the characteristics of the business relationship, the problem of knowing the network and the collaborative network is designed to try to collect information about Wang. The core issues are as follows:

1) Which colleagues do you often eat with?

2) Which colleagues do you usually have money with?

3) Which colleagues are you most happy to trust?

4) He is a very good friend

5) You know his parents

6) You want to know the job information and hot news, etc., who will you discuss with?

7) You have difficulties in life and work, who are you looking for?

8) Who do you often work with to complete tasks at work?

9) Where do you meet or meet with him most often?

10) When is the longest time between you and him?

11) When you are somewhere, you most often think about who you are about.

12) What is the frequency of your contact with him?

Here we use the method of snowballing to obtain the information, Wang as an individual who may be lost, we will ask it to provide a list according to the problem as much as possible, and then according to the list provided by Wang as a later research object, restricting our search depth The deeper reason is that we can determine who is our friend for the "observability boundary" of social networks, but our cognitive level of social networks will drop rapidly, so in this analysis, we Limit search to secondary level and be sufficiently complete with high accuracy. Here, the network of the business part is taken as an example to indicate the individual nodes by the serial number (see Figure 1). Here, the industry network, based on the survey of Wang, based on the list provided by the

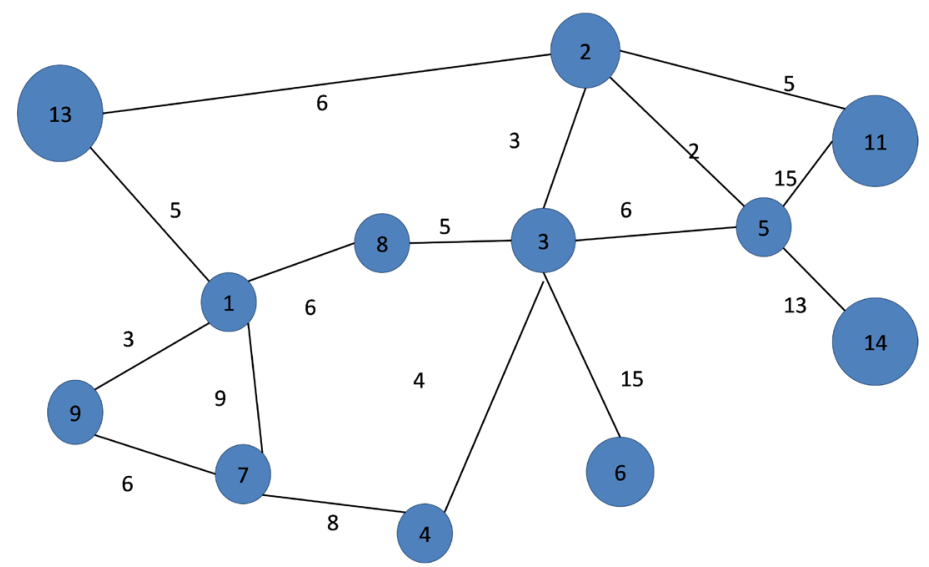

Figure 1. Schematic diagram of the business relationship network established by node 1 and node 5 . 
company, combined with the construction standards of the industry network, screened out several individuals who have a business relationship with Wang, using nodes 7, 8, 9, 13 in the figure. The remaining nodes are the individuals we screened out based on the same operations performed on these individuals. These nodes together form Wang's business relationship network. In the figure, node 1 is Wang. Here we use the intermediate centrality index as an example to calculate that the individual with greater influence in Wang's interpersonal network is the node No. 5, and the connection indicates that the two nodes have or have a career. Relationship, the weight indicates the strength of the relationship measured according to the survey, and the relationship strength calculated based on the result and the relationship frequency. The assignment to the individual social network is combined with the MIL method algorithm to first calculate the multipath as follows, in this case, It is determined by the interpersonal relationship network that the node 1 arrives at the multipath of the node 5, and the search is interrupted when the shortest path occurs when the node is not searchable or the node does not cooperate.

Combined with the above simulation network, the calculation process is as follows:

First calculate the shortest path between the 1 - 5 nodes in the figure as path (1.13.2.5), the shortest distance is 8 , and the path length is 4 .

When $i=1$, the edge between node 1 and node 13 is deleted, and the shortest path from node 1 to node 13 is (1.8.3.2.13), node 2 appears in the path, and the path with (13.2.5) is made. When splicing operation, delete path $(1-13)$ due to duplicate nodes.

Restore the edges of node 1 and node 13, when $i=2$, delete the edge between node 13 and node 2 , and calculate the shortest path between node 1 and node 2 as path 1 - 2 (1.8.3.2), in path 1 - 2 Get a new path (1.8.3.2.5) when doing splicing with path $2-5$.

Restore the edge between node 13 and node 2, calculate the edge between node 2 and node 5, calculate the minimum distance from node 1 to node 5 , and get the shortest path path $1-5(1.8 .3 .5)$

It is concluded that the above methods have obtained three paths from node 1 to node 5. Considering three cases, it avoids the situation that the shortest path is broken, and the suboptimal situation cannot be obtained in time, and the query is lost. The situation of the target. And in the calculation process, it is found that the distance of the node 3 directly to the node 5 is longer than the distance that the node 3 reaches the node 5 through the node 2 , and it is explained that even if the node 3 can directly contact the node 5 , the node is not found through the node 2 The efficiency of 5 is high, because the relationship between node 2 and node 5 is relatively high, and the relationship distance is relatively close, which is also in line with the situation of real interpersonal network, that is, the efficiency of the way through people with close relationship but direct contact but far distance It is much higher. 
For the three paths obtained in the previous case, a two-mode membership network is established for each node on the path, and a partial network diagram of the individual-time-location is obtained (see Figure 2). As follows:

The node 1, 2, 3, etc. of Figure 2 represent the target and its friends (relatives, fellow villagers), so that the network can not only see a specific time, place Which two identified individuals meet here, it can also be seen that when two individuals meet, they are most often at a certain time. In this illustration, node 1 most often meets at node 1 in the $08-11$ period, indicating that when node 1 suddenly loses connection, we can contact node 8 in the 08 - 11 period, the efficiency is relatively high, node 8 Both Node 5 and Node 5 prefer to go out at 14 $17 \mathrm{pm}$, indicating that we can have a higher probability of contacting Node 8 and Node 5 during that time period.

Through the application of social network tools, from the analysis of this network, we first get the entire interpersonal social network of the target individual. Through the analysis of the nodes in the network, we determine the nodes with relatively large influence in the personal social network. And the multiple paths of the target are determined. By analyzing the two-mode network of the nodes on the path, the time period and location where the probability of finding the node is the largest can be obtained.

\section{Conclusion}

This paper studies the application research of interpersonal social network to the search of borrowed and lost customers. Firstly, the construction of personal social network, including blood network, geography network, and business network, combined with the David scale to assign values to the network, and then combine the MIL algorithm measures the influential people in the personal social network, calculates the shortest path and multiple shortest paths between the

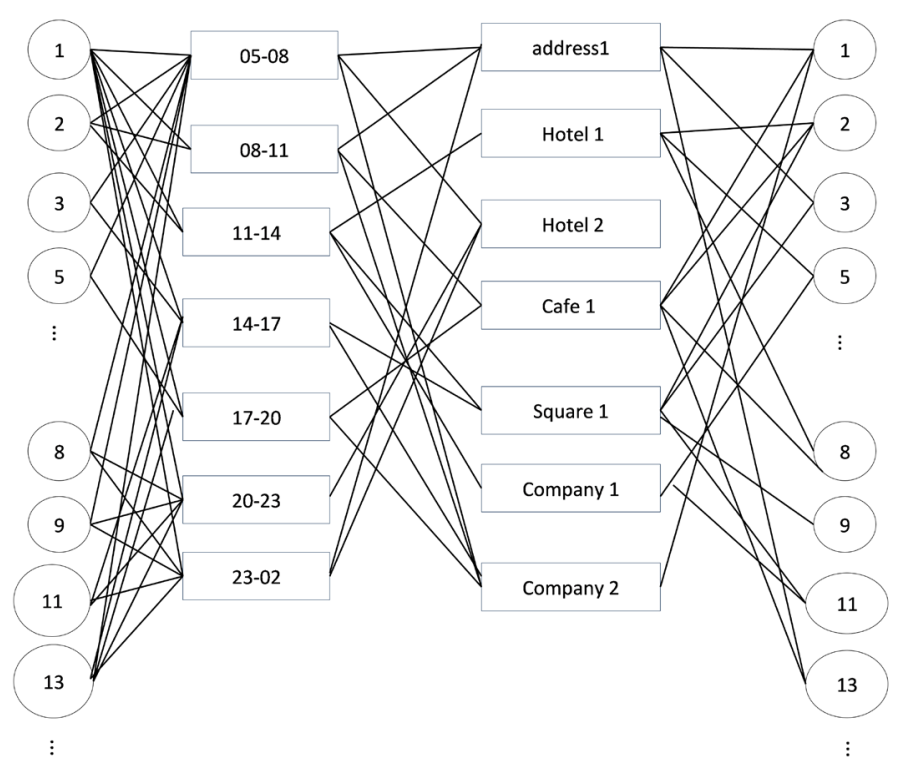

Figure 2. Partial network diagram of individual-time-location. 
target node and the set of influential nodes, and secondly constructs the twomode network between the nodes on the shortest path. So that we can obtain three key clues of people, time and place, so that we can make reasonable decisions according to the actual situation, improve the efficiency of our accurate and fast query to the target nodes, and finally propose us according to the norms and constraints of social networks. A fix was made to the target of the search, and then, combined with the entire study, an operational process was designed to face the borrowing and losing customers. Finally, combined with a simulation case, according to the operation flow proposed in this paper, the operation and practicability of the course of the process are visually indicated. The main contribution of this paper: At present, because of the imperfection of China's credit system, the people's cost of dishonesty is very low. Under the special national conditions of China, many people will choose to run away from the road when they face insolvency. After the literature, it was found that the social network tool can be used to solve this problem. This paper combines a real case of loss of association in Guangzhou, Guangdong Province, and innovatively combines social networks for analysis and search, and compares with the actual situation, and finds the algorithm. It does have some practicality. However, this paper still has the following shortcomings. The relationship in social networks tends to change at any time with time. Due to emotional intensity, relationship repair often involves some situations that are difficult to quantify. The construction of social networks lacks dynamics. Insufficient quantity, the setting of network weight is still not rigorous, and there is a lack of repair process for the lost customers who can be queried. This is also the main problem of future research.

\section{Acknowledgements}

The paper is supported by Natural Science Foundation of China (91646112); The Key Programs of Science and Technology Department of Guangdong Province (2016A020224001).

\section{Conflicts of Interest}

The authors declare no conflicts of interest regarding the publication of this paper.

\section{References}

[1] Ashta, A., Assadi, D. and Johnson, S. (2010) Online or Offline?: The Rise of "Peerto-Peer" Lending in Microfinance. IGI Global.

[2] Greiner, M.E. and Wang, H. (2010) Building Consumer-to-Consumer Trust in E-Finance Marketplaces: An Empirical Analysis. International Journal of Electronic Commerce, 15, 105-136. https://doi.org/10.2753/JEC1086-4415150204

[3] Lin, M., Prabhala, N.R., Viswanathan, S., et al. (2009) Social Networks as Signaling Mechanisms: Evidence from Online Peer-to-Peer Lending. Wise.

[4] Armendáriz, B. and Morduch, J. (2010) The Economics of Microfinance. 2nd Edition, Mit Press Books, 1151-1152.

[5] Freedman, S. and Jin, G.Z. (2017) The Information Value of Online Social Networks: Lessons from Peer-to-Peer Lending. International Journal of Industrial Or 
ganization, 51, 185-222. https://doi.org/10.1016/j.ijindorg.2016.09.002

[6] Chen, X., Zhou, L. and Wan, D. (2016) Group Social Capital and Lending Outcomes in the Financial Credit Market: An Empirical Study of Online Peer-to-Peer Lending. Electronic Commerce Research and Applications, 15, 1-13. https://doi.org/10.1016/j.elerap.2015.11.003

[7] Lin, M., Prabhala, N. and Viswanathan, S. (2013) Judging Borrowers by the Company They Keep: Friendship Networks and Information Asymmetry in Online Peerto-Peer Lending. Social Science Electronic Publishing, 59, 17-35. https://doi.org/10.1287/mnsc.1120.1560

[8] Izquierdo, L. and Hanneman, R. (2006) Introduction to the Formal Analysis of Social Networks Using Mathematica.

[9] Granovetter, M.S. (1977) The Strength of Weak Ties. Social Networks, 78, 347-367. https://doi.org/10.1016/B978-0-12-442450-0.50025-0

[10] Burt, J.T.R. (1996) Structural Holes: The Social Structure of Competition. Politiques et Management Public, 14.

[11] McKenney, D. and White, T. (2017) Selecting Transfer Entropy Thresholds for Influence Network Prediction. Social Network Analysis and Mining, 7.

[12] Hock, K., Ng, K.L. and Fefferman, N.H. (2010) Systems Approach to Studying Animal Sociality: Individual Position versus Group Organization in Dynamic Social Network Models. PLOS ONE, 5, e1578912.

[13] Karlan, D.S. (2007) Social Connections and Group Banking. Economic Journal, 117, F52-F84. https://doi.org/10.1111/j.1468-0297.2007.02015.x

[14] Lee, E. and Lee, B. (2012) Herding Behavior in Online P2P Lending: An Empirical Investigation. Electronic Commerce Research \& Applications, 11, 495-503. https://doi.org/10.1016/j.elerap.2012.02.001

[15] Chen, D., Lai, F. and Lin, Z. (2014) A Trust Model for Online Peer-to-Peer Lending: A Lender's Perspective. Information Technology \& Management, 15, 239-254. https://doi.org/10.1007/s10799-014-0187-Z

[16] Malekipirbazari, M. and Aksakalli, V. (2015) Risk Assessment in Social Lending via Random Forests. Pergamon Press, Inc., Oxford.

[17] Puro, L., Teich, J.E., Wallenius, H., et al. (2010) Borrower Decision Aid for Peopleto-People Lending. Decision Support Systems, 49, 52-60. https://doi.org/10.1016/j.dss.2009.12.009

[18] Collier, B.C. and Hampshire, R. (2010) Sending Mixed Signals: Multilevel Reputation Effects in Peer-to-Peer Lending Markets. ACM Conference on Computer Supported Cooperative Work, Savannah, 6-10 February 2010, 197-206. https://doi.org/10.1145/1718918.1718955

[19] Luo, B. and Lin, Z. (2013) A Decision Tree Model for Herd Behavior and Empirical Evidence from the Online P2P Lending Market. Information Systems \& e-Business Management, 11, 141-160. https://doi.org/10.1007/s10257-011-0182-4

[20] Carrillo, Á.E. and Riera, R.J. (2017) Measuring Social Capital: Further Insights. Gaceta Sanitaria, 31, 57-61. https://doi.org/10.1016/j.gaceta.2016.09.002

[21] Kraut, R.E., Resnick, P., Kiesler, S., et al. (2012) Building Successful Online Communities: Evidence-Based Social Design. The MIT Press, Cambridge. 